\title{
News Events and Their Relationship With US Vape Sales: An Interrupted Time Series Analysis
}

\author{
Kamila Janmohamed \\ Yale University \\ Shinpei Nakamura Sakai \\ Yale University \\ Abdul-Nasah Soale \\ Temple University \\ Laura Forastiere \\ Yale University \\ Navin Kumar ( $\square$ navin.kumar@yale.edu ) \\ Yale University
}

\section{Research Article}

Keywords: News events, Vaping, E-cigarette, Harm reduction

Posted Date: November 3rd, 2021

DOI: https://doi.org/10.21203/rs.3.rs-1005311/v1

License: (c) (1) This work is licensed under a Creative Commons Attribution 4.0 International License.

Read Full License

Version of Record: A version of this preprint was published at BMC Public Health on March 10th, 2022. See the published version at https://doi.org/10.1186/s12889-022-12858-x. 
Title: News events and their relationship with US vape sales: An interrupted time series analysis

Kamila Janmohamed ${ }^{1}$, Shinpei Nakamura-Sakai ${ }^{2}$, Abdul-Nasah Soale ${ }^{3}$, Laura Forastiere ${ }^{4}$, Navin Kumar ${ }^{5}$

1: Yale College, New Haven, CT, USA

2: Department of Statistics, Yale University, New Haven, CT, USA

3: Department of Statistical Science, Fox School of Business, Temple University, Philadelphia, PA, USA

4: Department of Biostatistics, Yale School of Public Health, New Haven, CT, USA

5: Yale School of Medicine, Section of Infectious Diseases, 135 College Street, Suite 323, New Haven, CT, 06510, USA

Correspondence to: Navin Kumar, Yale School of Medicine, Section of Infectious Diseases, 135 College Street, Suite 323, New Haven, CT, 06510, USA navin.kumar@yale.edu 
Title: News events and their relationship with US vape sales: An interrupted time series analysis

Abstract:

Objective

News coverage around vaping-related events may have furthered misconceptions regarding the relative harms of vapes. Such information may influence the decisions of individuals who smoke, around switching to vaping, potentially affecting the overall tobacco mortality burden. Thus, it is prudent to study how news events (e.g., 2019 vaping illness epidemic) are associated with vape sales in the United States, to possibly reduce the tobacco mortality burden.

\section{Methods}

We used weekly retail sales data for e-cigarettes (30 December 2018 - 28 December 2019) from the US retail scanner data compiled by the Nielsen Company. We used an interrupted time series design with segmented regression analysis to determine immediate and longerterm impacts of individual news events (e.g. Trump administration's planned ban on flavored vaping products) on vape sales, controlling for pre-existing trends.

Results

Unexpectedly, we noted a statistically significant positive relationship between vape sales and the CDC announcing an investigation into vaping-related illnesses (Change: 6.59\%, Estimate: 0.064; 95\% CI: 0.036, 0.092; P<0.001). We also observed a similar positive association between vape sales and the CDC's announcement on the link between Vitamin E acetate and EVALI (Change: 2.93\%, Estimate: 0.029; 95\% CI: 0.003, 0.055; P<0.05). There was a steep decline in sales after these events.

\section{Conclusions}

News events are associated with US vape sales. Findings have implications for the management of risk perceptions around vaping to improve health outcomes of tobacco users. Information-based policy instruments can be applied to balance the effects of news events 
that may influence vape sales.

Keywords: News events, Vaping, E-cigarette, Harm reduction 


\section{Introduction}

E-cigarette use (vaping) is likely less injurious to health compared to combustible cigarettes, due to reduced production of toxic chemicals and carcinogens (McNeill et al., 2018; US Food and Drug Administration and others, 2017). Despite this evidence, many people who smoke in the US perceive e-cigarettes (vapes) to be at least as dangerous to health as combustible cigarettes (McNeill et al., 2018; Nyman et al., 2019). Such misconceptions may influence the decisions of people who smoke and are unable to quit, around switching to vaping (Tattan-Birch et al., 2020) as a step toward smoking cessation. If an individual has been unsuccessful in attempts to quit smoking, switching to vaping may improve overall health outcomes (Polosa et al., 2016, 2017).

While youth vape use has declined since 2019, its prevalence remains high. As of 2020, 4.5\% of US adults and 3.6 million middle and high school students used e-cigarettes $(C D C, 2021)$. Sales from 2010-2016 show strong early growth followed by considerable slowing over time (Cantrell et al., 2020). In the US, the current consensus is that vaping is not a smoking cessation method, as no vape has been approved by the Food and Drug Administration as a safe and effective cessation product. The US scientific consensus is that vape aerosol contains fewer numbers and lower levels of toxicants than smoke from combustible tobacco cigarettes (Stratton et al., 2018). However, use of vapes results in dependence on the devices, but with apparently less risk and severity than that of combustible tobacco cigarettes (Stratton et al., 2018). News events may have furthered misconceptions around the relative harms of vapes (Hall, Gartner, \& Bonevski, 2021). For example, during the outbreak of vaping-related lung injury (EVALI), media coverage resulted in a 130\% increase in news articles warning against the dangers of vaping when the source of the epidemic was still unknown (Leas et al., 2020). Later, it emerged that most cases were related to consumption of vitamin E acetate, an additive included in some tetrahydrocannabinol (THC) devices (Hall et al., 2021).

News events can influence risk perceptions and normative perceptions around vaping (Dave 
et al., 2020a; Hall et al., 2021), especially around perceived risks of these products. We note that other factors can influence perceived risks, such as community, peers, word of mouth, advertising and promotion, and legislative regulation. Risk perceptions are associated with health-related behaviors and thus perceptions around vaping may influence use (Minton \& Gardiner, 2021; Pepper et al., 2019). Thus, news events may influence the decisions of people who smoke around switching to vaping, potentially affecting the overall tobacco mortality burden (Leas et al., 2021). Thus, we need to study how such news events are related to vape sales, to better understand how to promote vaping as a potential harm reduction technique for those who smoke and are unable to quit (Hartmann-Boyce et al., 2021; Grabovac et al., 2021).

We explored how various vaping-related news events (e.g. CDC announcing an investigation into vaping-related illnesses on August 172019 following an outbreak in 14 states, Trump administration plan to ban some vaping products on September 11 2019, FDA's warning to consumers against the use of vape products containing THC on October 4 2019, CDC's announcement on the link between Vitamin E acetate and EVALI on November 8 2019) were associated with US vape sales. We aim to provide insight around improving health outcomes of people who smoke, amid increased risk perception around vaping (Dave, Dench, Kenkel, Mathios, \& Wang, 2020b; Kreslake, Diaz, Shinaba, Vallone, \& Hair, 2021).

\section{Method}

Data

Weekly retail sales data for e-cigarettes (30 December 2018 - 28 December 2019) was obtained from US retail scanner data compiled by the Nielsen Company. Weekly sales data was denominated in US dollars (USD). This data represented weekly sales of e-cigarettes in Nielsen's participating retailers, such as food, drug and mass stores in 52 US markets and convenience stores in a subset of those markets. Nielsen retail sales data does not include e-cigarette sales in non-participating retailers, vape stores and online e-cigarettes sales. 
Selection of events of interest

We first assembled a preliminary list of vaping-related events based on a review of online news sites and peer-reviewed vaping research articles and consultation with experts on vaping. Two authors manually reviewed resulting events to assess relevance to the study (Cohen's Kappa >90\%), resulting in a list of five events. Examples of news sites are as follows: businessinsider.com/timeline-of-vape-related-illnesses-and-deaths-2019-9;

https://www.beckershospitalreview.com/quality/how-vaping-turned-into-a-public-health-emergencytimeline-of-key-events.html;

https://www.cdc.gov/tobacco/basicinformation/e-cigarettes/severe-lung-disease.html.

Regarding vaping experts, we identified key scholars in vaping through the number of articles ( $>10)$ published regarding vaping. We then contacted the identified researchers and asked them to assist. The original five events are as follows: 17 August 2019, CDC announced that they would be investigating cases of vaping-related illnesses; 11 September 2019, Trump administration considers ban on vaping products; 24 September 2019, Massachusetts bans vaping products; 4 October 2019, The FDA warned consumers not to use any THC-containing vapes; 8 November 2019, Vitamin E acetate responsible for EVALI (CDC announcement).

We then conducted preliminary analyses with these events to determine the ones that were associated with a shift in sales. The final four vaping-related news events were as follows: 1) CDC announcing an investigation into vaping-related illnesses on August 172019 following an outbreak in 14 states (CDC, 2019); 2) Trump administration plan to ban some vaping products on September 112019 (The White House, 2019); 3) FDA's warning to consumers against the use of vape products containing THC on October 42019 (Berke, 2019); 4) CDC's announcement on the link between Vitamin E acetate and EVALI on November 8 2019 (Grady, 2019).

\section{Statistical analysis}

We used an interrupted time series design with segmented regression analysis to determine 
immediate and longer-term impacts of individual news events on vape sales, controlling for other time-dependent covariates (US-based hospitalizations from vaping, US weekly retail sales data for combustible cigarettes), as indicated below. The unit of analysis (dependent variable) was log-transformed weekly retail sales data for e-cigarettes. Interrupted time series analysis can validate whether certain news events have an effect significantly greater than the underlying trend by collecting data at multiple instances overtime before and after news events (Ramsay, Matowe, Grilli, Grimshaw, \& Thomas, 2003). Interrupted time series is the strongest quasi-experimental design to assess longitudinal effects of time-delimited treatments or interventions (Peng et al., 2006). This design was appropriate as data was collected at multiple time points and we wanted to detect if an intervention (news events) had a significantly greater effect than another underlying trend (Kontopantelis et al., 2015). The goal of interrupted time series analysis is to estimate the interaction terms between implementation of a news event and time. This binary variable captures the interaction between the news events occurrence and time. The regression coefficient on this variable is interpreted as the immediate impact on the level of the outcome (vape sales) (Penfold \& Zhang, 2013).

We first conducted a visual examination on the pattern of the time series by plotting them and generating auto-correlation and partial correlation plots. No seasonal patterns were identified. Auto-correlation was tested with the Durbin-Watson test. Nonstationarity was identified using the augmented Dickey-Fuller test and corrected through differencing. An autoregressive moving average (ARIMA) model of order 1 was fit against a white noise series generated from the stationarized data to determine optimal model parameters. Both models included binary variables for events $(0=$ dates before the event, $1=$ dates after the event), time (1 was denoted for the first week and numbered sequentially after), and time since each event ( 1 was denoted for the first week after each event and numbered sequentially after). 
We used US-based hospitalizations from vaping and US weekly retail sales data for combustible cigarettes (denominated in USD) as control variables. We derived hospitalizations from vaping by summing the number of individuals hospitalized with lung injury associated with e-cigarette use or vaping in the US on a particular week, from CDC data (Centers for Disease Control and Prevention and others, 2019). Weekly retail sales data for combustible cigarettes was obtained from the US retail scanner data compiled by the Nielsen Company. This data represented weekly sales of cigarettes in Nielsen's participating retailers. These control variables may address underlying time-varying factors possibly influencing vape sales. Including these factors may also control for pre-existing trends, essentially to avoid confusing a change due to these factors with a change due to the news events. By considering a broader picture of what may influence vape sales, we can better test the claims relation to the association between specific news events and vape sales. We calculated $95 \%$ confidence intervals for the association of each event with vape sales. We only reported results where the key predictor variable and its corresponding interaction term were significant at the $\mathrm{P}<0.05$ level. To better understand the trend of vape sales if the vaping-related events had not occurred, using data from 30 December 2018 to 17 August 2019 and the identical model above [ARIMA $(1,1,0)]$, we predicted vape sales from 18 August 2019 to 28 December 2019. Analysis was conducted using $\mathrm{R}$ with the following packages: tseries, forecast and lmtest (Trapletti \& Hornik, 2019; Hyndman et al., 2020; Hothorn et al., 2019).

\section{Results}

The mean weekly retail sales data for e-cigarettes (30 December 2018 - 28 December 2019) was $\$ 151,304,340(\mathrm{SD}=\$ 15,813,160)$.

\section{INSERT FIGURE 1 HERE}

Figure 1 illustrates the $\mathrm{ACF}$ and $\mathrm{PACF}$ plots for pre-EVALI e-cigarette sales data. The single statistically significant peak in the PACF plot indicates the suitability of a first-order 
ARIMA model. This is corroborated by the Durbin-Watson test $(\mathrm{p}<0.001)$, which suggests that true auto-correlation in the model is greater than 0. Furthermore, the Augmented Dickey-Fuller test (See Supplementary Table B) indicates that the series is stationary only for a model with drift, trend and 0 lags.

\section{INSERT FIGURE 2 HERE}

Figure 2 illustrates vape sales over time (30 December 2018 - 28 December 2019). Vape sales were originally increasing, perhaps due to the rising popularity of vaping, with a continued increase after $\mathrm{CDC}$ announcing an investigation into vaping-related illnesses (August 17 2019), possibly due to individuals who vape stockpiling of the product. There was then a steep decline, perhaps due to negative perceptions around vaping influencing sales. Sales rose after FDA's warning to consumers against the use of vape products containing THC (October 4 2019), with a continued increase after CDC's announcement on the link between Vitamin E acetate and EVALI (November 8 2019), possibly to due stockpiling of vapes. There was a subsequent decline shortly after CDC's announcement on the link between Vitamin E acetate and EVALI.

Table 1 reports the estimates of the interrupted time series design with segmented regression analysis across various news events (See Supplement for full results). We noted a statistically significant positive relationship between vape sales and the CDC announcing an investigation into vaping-related illnesses (Change: 6.59\%, Estimate: 0.064; 95\% CI: 0.036, 0.092; $\mathrm{P}<0.001)$. We observed a similar positive association between vape sales and the CDC's announcement on the link between Vitamin E acetate and EVALI (Change: 2.93\%, Estimate: 0.029; 95\% CI: 0.003, 0.055; $\mathrm{P}<0.05)$.

\section{INSERT FIGURE 3 HERE}

Figure 3 details predicted vape sales assuming the vaping-related events had not occurred. 
Table 1. Estimates of the interrupted time series design with segmented regression analysis across various vaping-related events

\begin{tabular}{lcccc}
\hline Event & $\begin{array}{c}\text { Estimate } \\
(\mathbf{9 5 \%} \mathbf{C I})\end{array}$ & $\mathbf{p}$ & $\begin{array}{c}\text { Interaction } \\
(\mathbf{9 5 \%} \mathbf{C I})\end{array}$ & $\begin{array}{c}\mathbf{p} \\
\text { interaction }\end{array}$ \\
\hline $\begin{array}{l}\text { CDC announcing an } \\
\text { investigation into } \\
\text { vaping-related } \\
\text { illnesses }\end{array}$ & $\begin{array}{c}0.064 \\
(0.036,0.092)\end{array}$ & $\mathbf{p}<\mathbf{0 . 0 0 1}$ & $\begin{array}{c}-0.064 \\
(-0.075,-0.052)\end{array}$ & $\mathbf{p}<\mathbf{0 . 0 0 1}$ \\
$\begin{array}{l}\text { Trump administration } \\
\text { plan to ban some }\end{array}$ & 0.014 & & & \\
vaping products & $(-0.018,0.045)$ & 0.398 & $(0.020,0.056)$ & $\mathbf{p}<0.001$ \\
$\begin{array}{l}\text { FDA warns } \\
\text { consumers against the }\end{array}$ & -0.006 & & & \\
$\begin{array}{l}\text { use of vape products } \\
\text { containing THC }\end{array}$ & $(-0.034,0.021)$ & 0.651 & $(0.012,0.046)$ & $\mathbf{p}<0.001$ \\
$\begin{array}{l}\text { CDC announces link } \\
\text { between Vitamin E } \\
\text { acetate and EVALI }\end{array}$ & \begin{tabular}{l}
$(0.003,0.055)$ \\
\hline
\end{tabular}
\end{tabular}

Bold p-values indicate statistical significance $(\mathrm{P}<0.05)$ for both the news event (key dependent variable) and the corresponding interaction term $(\mathrm{P}<0.05)$.

Results indicated a continued increase in forecasted sales, suggesting that EVALI resulted in a $21 \%$ decrease in total sales worth $\$ 767,099,216$.

\section{Discussion}

We found an association between the two CDC announcements regarding EVALI and a temporary increase in vape sales, with a steep decline in sales after these events. While we believed that news events around vape harms would be associated with reduced sales, based on past work (Dave et al., 2020a; Duong \& Liu, 2018), we observed some converse results. We suggest that some CDC announcements around vaping may have led people who vape to believe that sales would be restricted, perhaps influencing them to purchase more vapes before a moratorium on sales. Some vape stores suggested that consumers stock up on vapes 
during a crisis (Ramamurthi et al., 2020), and government bans may influence consumers to stock up on tobacco products (Kamiński et al., 2020). Although these results suggest that some news events (Trump administration plan to ban some vaping products on September 11 2019, FDA's warning to consumers against the use of vape products containing THC on October 4 2019) were not associated with a decrease in sales, this does not mean that such events did not dissuade some individuals who smoke from switching to vaping. It may be that the temporary increase in sales was driven by consumers who already vaped, temporarily obscuring the possible decline of individuals who smoke in switching to vaping. We suggest that the steep decline in sales shortly after each CDC announcement around EVALI, further evidenced by the great difference in forecasted vape sales versus actual sales, may be driven by an increase in risk perceptions around vaping, with individuals who smoke less likely to purchase vapes (Kumar et al., 2021; Erku et al., 2021). These findings may suggest that increased risk perceptions around vaping may influence fewer individuals who smoke from making the switch, perhaps increasing the tobacco mortality burden (Hartmann-Boyce et al., 2021). We suggest the need for additional qualitative research to better understand how individuals who smoke conceptualized risk perceptions around vaping during news events.

The strength of our work is the use of robust statistical methods to explore how news events are associated with US vape sales. Such outcome measurement is central to understanding how news events may shift vape sales, allowing for accurate public health messaging around vaping when such events arise. Messaging may encourage some people who smoke to switch to vaping as a step toward abstinence, improving health outcomes, even when news outlets display inordinately negative coverage regarding vaping. We also note that messaging by public health authorities which supports vaping may inadvertently decrease risk perceptions among young people or persons who do not smoke, who may then be more likely to try vaping, increasing their risk (Balfour et al., 2021; Brown et al., 2020). We do not support discouraging news warning about the risks of e-cigarettes, but a careful consideration of the balance of risks related to promoting vaping as a harm reduction approach. Public 
health authorities can also conduct interventions to balance the rhetoric of news events. Interventions that ask respondents to judge information accuracy around vaping (Pennycook \& Rand, 2019; Barnett, Hoskins, Alhoti, \& Carpenter, 2009), may nudge individuals toward accurate information regarding vaping during news events which possibly distort vaping perceptions. Future research can detail how some news events have a greater effect on vape sales compared to others, and address how best to intervene around disproportionate responses to vaping news events.

A key limitation is that we cannot say with certainty that news events caused a shift in vape sales or whether there were other underlying factors. We provide correlational evidence, but cannot make causal claims. We also limited in our ability to adjust for other possible confounders e.g. sales of nicotine replacement produces or cannabis-related sales. We were unable to measure other factors that may have a role on vape sales, such as community and peer influence, word of mouth, advertising and promotion, and legislative regulation. We were not able to account for the connotation of media messages using techniques such as sentiment analysis (Liu, 2011). Our data did not capture online sales and it is unclear what proportion of sales are online.

We indicated that news events may be associated with changes in US vape sales. We suggest that public health messaging may ensure that those who smoke and wish to quit are not dissuaded from switching to vaping. Findings have implications for the management of risk perceptions around vaping to improve health outcomes of tobacco users. Information-based policy instruments can be applied to balance the negative effects of news events that may affect vape sales. 
213

214

215

\title{
Declarations
}

\section{Ethical Approval and Consent to participate}

Approval and informed consent were not needed as we used an anonymized dataset. Yale University IRB committee guidelines waived the need for informed consent and ethical approval. Research was performed in accordance with the Declaration of Helsinki. This study was pre-registered on the Open Science Framework (OSF.IO/HZVJB).

\section{Consent for publication}

\author{
Not applicable
}

\section{Availability of data and materials}

The datasets used and analyzed during the current study available from the corresponding author on reasonable request.

\section{Competing interests}

Navin Kumar, Abdul-Nasah Soale, Laura Forastiere declare financial support through a grant from the Foundation for a Smoke-Free World, a US nonprofit 501(c)(3) private foundation with a mission to end smoking in this generation. The Foundation accepts charitable gifts from PMI Global Services Inc. (PMI); under the Foundation's Bylaws and Pledge Agreement with PMI, the Foundation is independent from PMI and the tobacco industry. There are no financial relationships with any other organisations that might have an interest in the 
submitted work in the previous three years; and no other relationships or activities that could appear to have influenced the submitted work. All remaining authors do not declare any conflicts of interest.

\section{Funding}

This study was funded with a grant from the Foundation for a Smoke-Free World, a US nonprofit 501(c)(3) private foundation with a mission to end smoking in this generation. The Foundation accepts charitable gifts from PMI Global Services Inc. (PMI); under the Foundation's Bylaws and Pledge Agreement with PMI, the Foundation is independent from PMI and the tobacco industry. The contents, selection, and presentation of facts, as well as any opinions expressed herein are the sole responsibility of the authors and under no circumstances shall be regarded as reflecting the positions of the Foundation for a SmokeFree World, Inc.

\section{Author's contributions}

NK wrote the first draft. KJ, SN, AS, LF, NK contributed to the manuscript write-up and review.

\section{Acknowledgements}

We thank the editor and reviewers for their comments. This study was pre-registered on the Open Science Framework (OSF.IO/HZVJB). This study was funded with a grant from the Foundation for a Smoke-Free World, a US nonprofit 501(c)(3) private foundation with a mission to end smoking in this generation. The Foundation accepts charitable gifts from PMI Global Services Inc. (PMI); under the Foundation's Bylaws and Pledge Agreement 
with PMI, the Foundation is independent from PMI and the tobacco industry. The contents, selection, and presentation of facts, as well as any opinions expressed herein are the sole responsibility of the authors and under no circumstances shall be regarded as reflecting the positions of the Foundation for a Smoke-Free World, Inc.

\section{References}

Balfour, D. J., Benowitz, N. L., Colby, S. M., Hatsukami, D. K., Lando, H. A., Leischow, S. J., . . o others (2021). Balancing consideration of the risks and benefits of e-cigarettes. American Journal of Public Health(0), e1-e12.

Barnett, P. A., Hoskins, C. E., Alhoti, J. A., \& Carpenter, L. J. (2009). Reducing public misinformation about organ donation: An experimental intervention. Journal of Social Distress and the Homeless, 18(1-2), 57-73.

Berke, J. (2019). The fda just leveled a stark warning against using any vapes containing thc amid an outbreak of lung disease. Retrieved from https:// WwW. businessinsider.com/fda-warns-consumers-not-to-use-marijuana-vapes -amid-lung-disease-crisis-2019-10 (Accessed 2020-06-30)

Brown, R., Bauld, L., de Lacy, E., Hallingberg, B., Maynard, O., McKell, J., .. Moore, G. (2020). A qualitative study of e-cigarette emergence and the potential for renormalisation of smoking in uk youth. International Journal of Drug Policy, 75, 102598.

Cantrell, J., Huang, J., Greenberg, M., Willett, J., Hair, E., \& Vallone, D. (2020). History and current trends in the electronic cigarette retail marketplace in the united states: 2010-2016. Nicotine and Tobacco Research, 22(5), 843-847.

CDC. (2019). Cdc, states investigating severe pulmonary disease among people who use e-cigarettes. Retrieved from https://www.cdc.gov/media/releases/2019/s0817 -pulmonary-disease-ecigarettes.html (Accessed 2020-06-30) 
Cdc. (2021, Apr). Centers for Disease Control and Prevention. Retrieved from https://www.cdc.gov/tobacco/basic_information/e-cigarettes/about-e -cigarettes.html

Centers for Disease Control and Prevention and others. (2019). Outbreak of lung injury associated with e-cigarette use, or vaping. Retrieved October, 23, 2019.

Dave, D., Dench, D., Kenkel, D., Mathios, A., \& Wang, H. (2020a). News that takes your breath away: Risk perceptions during an outbreak of vaping-related lung injuries. doi: $10.3386 / \mathrm{w} 26977$

Dave, D., Dench, D., Kenkel, D., Mathios, A., \& Wang, H. (2020b). News that takes your breath away: risk perceptions during an outbreak of vaping-related lung injuries. Journal of Risk and Uncertainty, 60(3), 281-307.

Duong, H. T., \& Liu, J. (2018). Vaping in the news: The influence of news exposure on perceived e-cigarette use norms. American Journal of Health Education, 50(1), 25-39. doi: 10.1080/19325037.2018.1548315

Erku, D. A., Bauld, L., Dawkins, L., Gartner, C. E., Steadman, K. J., Noar, S. M., ... Morphett, K. (2021). Does the content and source credibility of health and risk messages related to nicotine vaping products have an impact on harm perception and behavioural intentions? a systematic review. Addiction.

Grabovac, I., Oberndorfer, M., Fischer, J., Wiesinger, W., Haider, S., \& Dorner, T. E. (2021). Effectiveness of electronic cigarettes in smoking cessation: a systematic review and meta-analysis. Nicotine and Tobacco Research, 23(4), 625-634.

Grady, D. (2019). Vaping illnesses are linked to vitamin e acetate, c.d.c. says. Retrieved from https://www.nytimes.com/2019/11/08/health/vaping-illness-cdc.html (Accessed 2020-06-30)

Hall, W., Gartner, C., \& Bonevski, B. (2021). Lessons from the public health responses to the us outbreak of vaping-related lung injury. Addiction, 116(5), 985-993.

Hartmann-Boyce, J., McRobbie, H., Butler, A. R., Lindson, N., Bullen, C., Begh, R., ... 
others (2021). Electronic cigarettes for smoking cessation. Cochrane database of systematic reviews $(9)$.

Hothorn, T., Zeileis, A., Farebrother, R. W., Cummins, C., Millo, G., \& Mitchell, D. (2019). lmtest: Testing linear regression models [Computer software manual]. Retrieved from https://cran.r-project.org/web/packages/lmtest (R package version 0.9-37.)

Hyndman, R., Athanasopoulos, G., Bergmeir, C., Caceres, G., Chhay, L., O'Hara-Wild, M., ... Yasmeen, F. (2020). forecast: Forecasting functions for time series and linear models [Computer software manual]. Retrieved from http://pkg.robjhyndman.com/ forecast ( $R$ package version 8.12)

Kamiński, M., Muth, A., \& Bogdański, P. (2020). Smoking, vaping, and tobacco industry during covid-19 pandemic: Twitter data analysis. Cyberpsychology, Behavior, and Social Networking, 23(12), 811-817.

Kontopantelis, E., Doran, T., Springate, D. A., Buchan, I., \& Reeves, D. (2015). Regression based quasi-experimental approach when randomisation is not an option: interrupted time series analysis. $b m j, 350, \mathrm{~h} 2750$.

Kreslake, J. M., Diaz, M. C., Shinaba, M., Vallone, D. M., \& Hair, E. C. (2021). Youth and young adult risk perceptions and behaviours in response to an outbreak of ecigarette/vaping-associated lung injury (evali) in the usa. Tobacco Control.

Kumar, N., Hampsher, S., Walter, N., Nyhan, K., Ding, Q., Tracy, K., ... Forastiere, L. (2021). Interventions to mitigate vaping misinformation: Protocol for a scoping review.

Leas, E. C., Nobles, A. L., Caputi, T. L., Dredze, M., Zhu, S.-H., Cohen, J. E., \& Ayers, J. W. (2020). News coverage of the e-cigarette, or vaping, product use associated lung injury (evali) outbreak and internet searches for vaping cessation. Tobacco Control. doi: 10.1136/tobaccocontrol-2020-055755

Leas, E. C., Nobles, A. L., Caputi, T. L., Dredze, M., Zhu, S.-H., Cohen, J. E., \& Ayers, J. W. (2021). News coverage of the e-cigarette, or vaping, product use associated lung injury (evali) outbreak and internet searches for vaping cessation. Tobacco control, 
$30(5), 578-582$.

Liu, B. (2011). Opinion mining and sentiment analysis. In Web data mining (pp. 459-526). Springer.

McNeill, A., Brose, L. S., Calder, R., Bauld, L., \& Robson, D. (2018). Evidence review of e-cigarettes and heated tobacco products 2018. A report commissioned by Public Health England. London: Public Health England, 6.

Minton, E. A., \& Gardiner, P. (2021). The missing role of moral values in anti-vaping messaging. Journal of Consumer Affairs.

Nyman, A. L., Huang, J., Weaver, S. R., \& Eriksen, M. P. (2019). Perceived comparative harm of cigarettes and electronic nicotine delivery systems. JAMA Network Open, 2(11), e1915680-e1915680.

Penfold, R. B., \& Zhang, F. (2013). Use of interrupted time series analysis in evaluating health care quality improvements. Academic pediatrics, 13(6), S38-S44.

Peng, R. D., Dominici, F., \& Louis, T. A. (2006). Model choice in time series studies of air pollution and mortality. Journal of the Royal Statistical Society: Series A (Statistics in Society), $169(2), 179-203$.

Pennycook, G., \& Rand, D. G. (2019). Fighting misinformation on social media using crowdsourced judgments of news source quality. Proceedings of the National Academy of Sciences, 116(7), 2521-2526.

Pepper, J. K., Squiers, L. B., Peinado, S. C., Bann, C. M., Dolina, S. D., Lynch, M. M., ... McCormack, L. A. (2019). Impact of messages about scientific uncertainty on risk perceptions and intentions to use electronic vaping products. Addictive behaviors, 91, $136-140$.

Polosa, R., Cibella, F., Caponnetto, P., Maglia, M., Prosperini, U., Russo, C., \& Tashkin, D. (2017). Health impact of e-cigarettes: a prospective 3.5-year study of regular daily users who have never smoked. Scientific Reports, 7(1). doi: 10.1038/s41598-017-14043-2

Polosa, R., Morjaria, J. B., Caponnetto, P., Prosperini, U., Russo, C., Pennisi, A., \& Bruno, 
C. M. (2016). Evidence for harm reduction in copd smokers who switch to electronic cigarettes. Respiratory Research, 17(1). doi: 10.1186/s12931-016-0481-x

Ramamurthi, D., Chau, C., \& Jackler, R. K. (2020). Exploitation of the covid-19 pandemic by e-cigarette marketers. Tobacco Control.

Ramsay, C. R., Matowe, L., Grilli, R., Grimshaw, J. M., \& Thomas, R. E. (2003). Interrupted time series designs in health technology assessment: lessons from two systematic reviews of behavior change strategies. International journal of technology assessment in health care, 19(4), 613-623.

Stratton, K., Kwan, L. Y., Eaton, D. L., et al. (2018). Public health consequences of e-cigarettes: consensus study report. Public health consequences of e-cigarettes: consensus study report.

Tattan-Birch, H., Brown, J., Shahab, L., \& Jackson, S. E. (2020). Association of the us outbreak of vaping-associated lung injury with perceived harm of e-cigarettes compared with cigarettes. JAMA Network Open, 3(6). doi: 10.1001/jamanetworkopen.2020 .6981

The White House. (2019). Remarks by president trump in meeting on $e$ cigarettes. Retrieved from https://www.whitehouse.gov/briefings-statements/ remarks-president-trump-meeting-e-cigarettes/ (Accessed 2020-06-30)

Trapletti, A., \& Hornik, K. (2019). tseries: Time series analysis and computational finance [Computer software manual]. Retrieved from https://CRAN.R-project.org/ package=tseries ( $\mathrm{R}$ package version 0.10-47.)

US Food and Drug Administration and others. (2017). Fda announces comprehensive regulatory plan to shift trajectory of tobacco-related disease, death. Agency to pursue lowering nicotine in cigarettes to non-addictive levels and create more predictability in tobacco regulation. Maryland. 
${ }_{384}$ Tables 


\section{Figures captions}

1. Vape sales scatterplot and trends with a timeline of vaping-related news events.

(a) August 17 2019: CDC announces investigation into vaping-related illnesses

(b) September 11 2019: Trump administration considers ban on vaping products

(c) October 4 2019: FDA warns against using vape products containing THC

(d) November 8 2019: CDC announces relationship between Vitamin E acetate and lung injury outbreak

Note. Association between vape sales and exposure to news events. The solid line indicated the smoothed weekly vape sales with the corresponding confidence interval (in grey) and was obtained by fitting the date of the vape sales to the amount of vape sales using an interrupted time series design with segmented regression analysis. Red boxes denoted news events that had statistically significant association $(\mathrm{p}<0.05)$ with shifts in vape sales.

2. Vape sales forecast with ARIMA $(1,1,0)$ assuming EVALI events had not occurred. Note. Red dotted line and corresponding confidence interval (in grey) represented forecast with identical ARIMA $(1,1,0)$ model as Figure 1. The black lines indicated actual weekly vape sales. 
402 Figures 
Sensitivity Analysis of Vape Sales
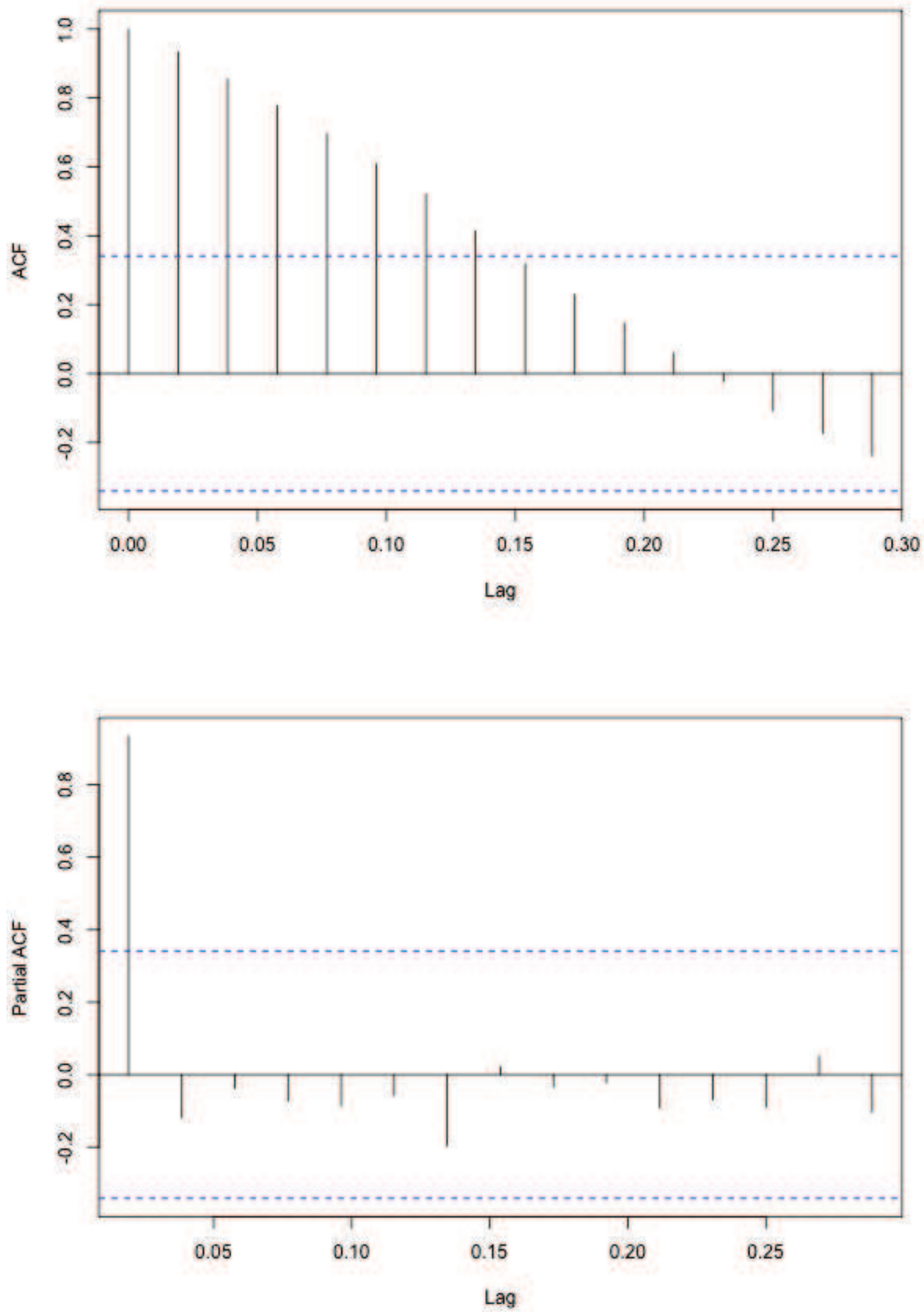

Figure 1 


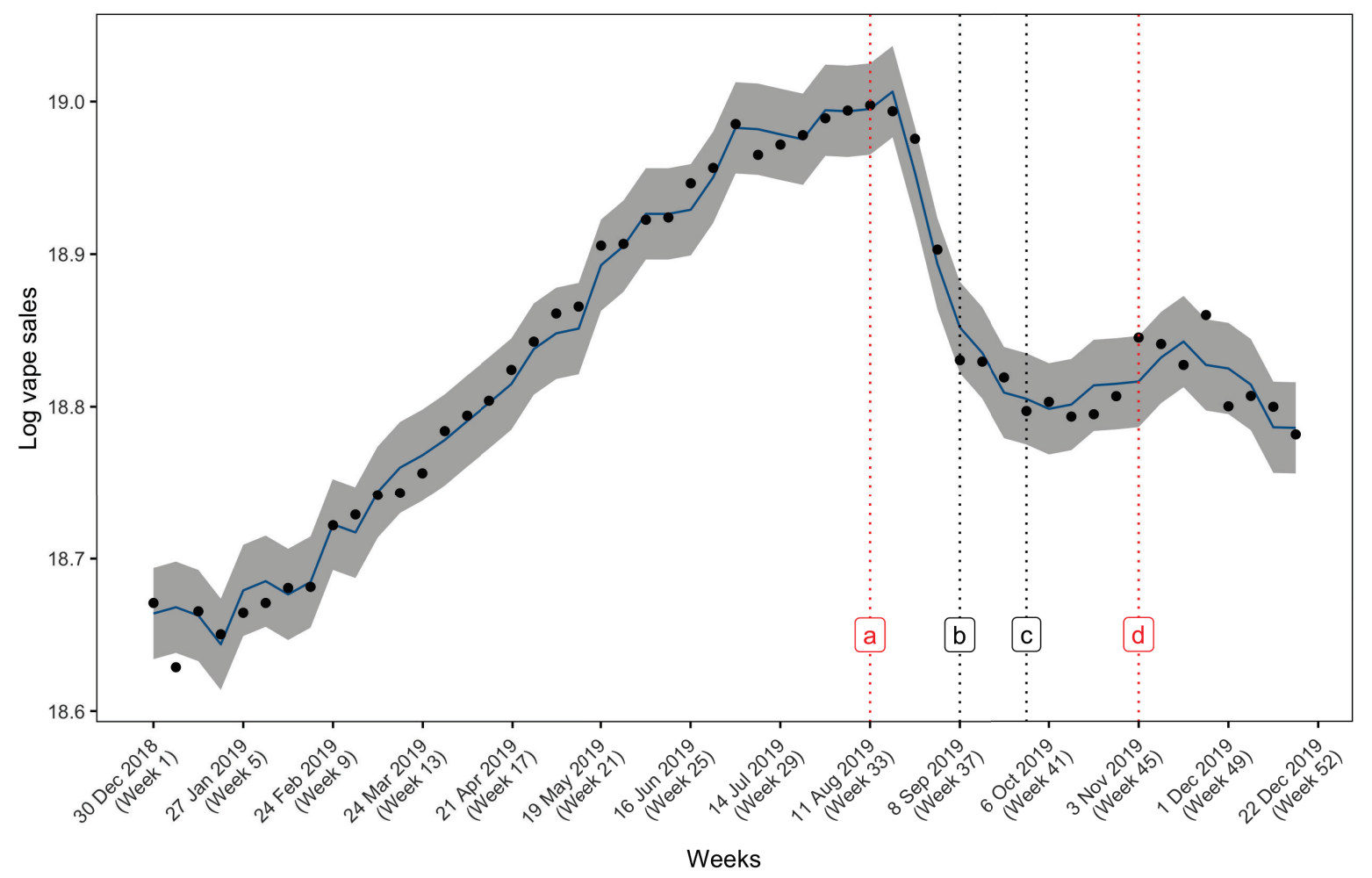

Figure 2 


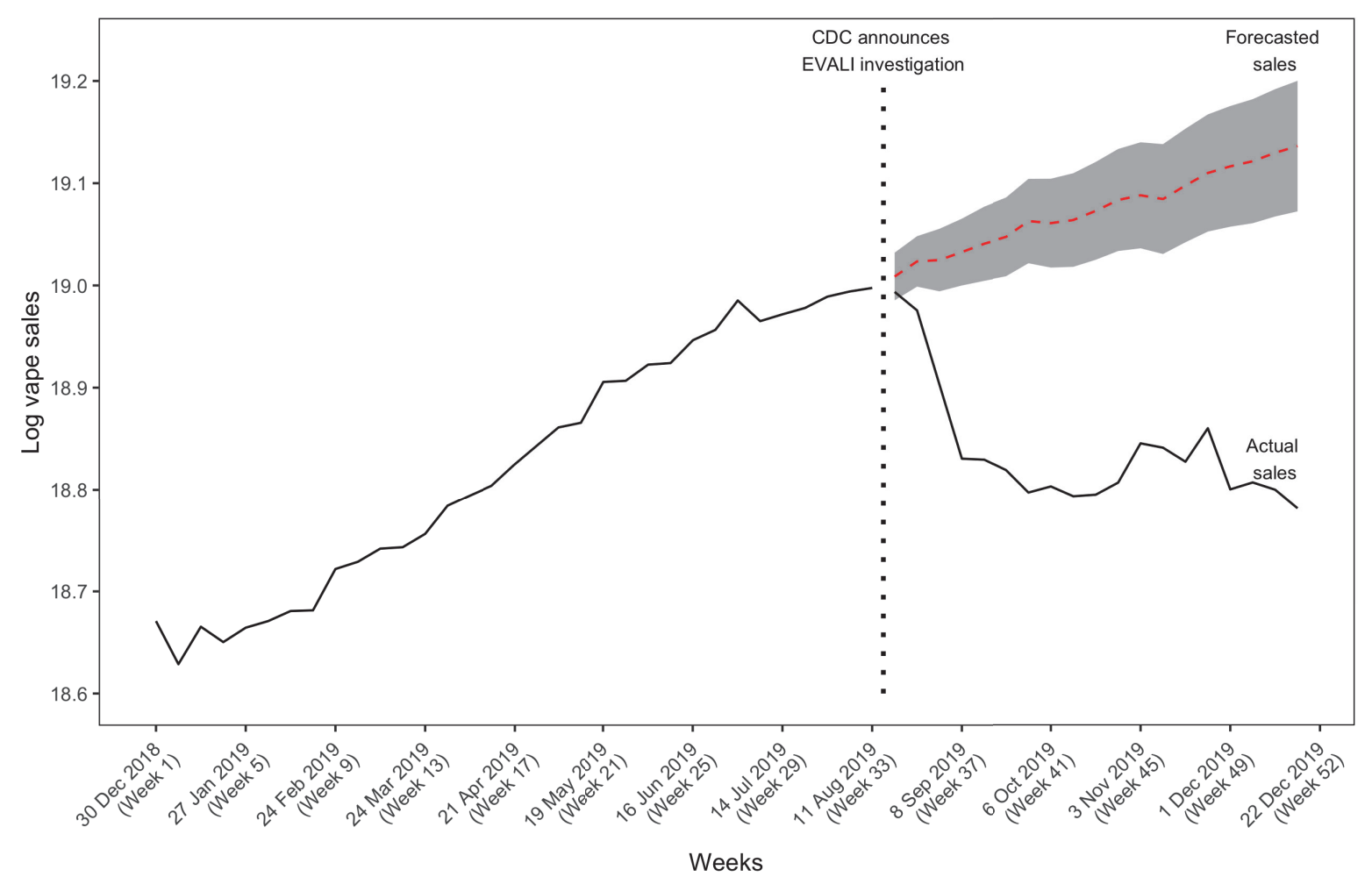

Figure 3 


\section{Supplementary Files}

This is a list of supplementary files associated with this preprint. Click to download.

- Supplementarytables.pdf 